\title{
Atividade Antifúngica do Óleo Essencial de Rosmarinus officinalis Sobre a Cinética do Crescimento de Candida albicans e Candida tropicalis
}

\author{
Antifungal Activity of Rosmarinus officinalis Essential Oil on Growth \\ Kinetics of Candida albicans and Candida tropicalis
}

\section{RESUMO}

Objetivo: Avaliar a atividade antifúngica do óleo essencial de Rosmarinus officinalis sobre a cinética do crescimento de Candida albicans (ATCC289065) e C. tropicalis (ATCC40042). Material e Métodos: Em tubos de vidro estéreis foram adicionados $1,8 \mathrm{~mL}$ de Caldo Sabouraud Dextrose, $0,2 \mathrm{~mL}$ das suspensões fúngicas $\left(1,5 \times 10^{6} \mathrm{UFC} / \mathrm{mL}\right)$ e $2 \mathrm{~mL}$ da diluição do óleo essencial de $R$. officinalis nas concentrações $2 \%$ e $1 \%$. Posteriormente, realizou-se a semeadura de $10 \mu \mathrm{L}$ das soluções testadas nos tempos zero, 30,60 e 120 minutos. Após incubação a $37^{\circ} \mathrm{C}$ por 24 horas, determinou-se o total de UFC/mL para cada amostra. A Solução de Hipoclorito de Sódio a $0,5 \%$ e o meio de cultura sem a adição de antimicrobianos funcionaram como controle. Resultados: O $R$. officinalis provocou, para $C$. albicans e C. tropicalis, acentuação na curva de morte microbiana nos intervalos 30 minutos $\left(<3,5 \times 10^{4} \mathrm{UFC} / \mathrm{mL}\right)$ e 120 minutos $\left(<9 \times 10^{4} \mathrm{UFC} / \mathrm{mL}\right)$, respectivamente. Para C. albicans, observou-se diferença estatisticamente significante $(p-$ valor $<0,01$ ) entre o controle de crescimento e o total de UFC/ $\mathrm{mL}$ produzido pelos produtos testados. Para C. tropicalis, verificou-se diferença estatisticamente significante ( $p$ valor $<0,01$ ) entre o efeito provocado pelo $R$. officinalis e o total de UFC/ml do controle de crescimento e do Hipoclorito de Sódio. Conclusão: O óleo essencial de $R$. officinalis apresentou ação antifúngica sobre o crescimento de $C$. albicans e $C$. tropicalis, destacando-se maior efeito diante do maior tempo de contato.

\section{DESCRITORES}

Microbiologia. Rosmarinus officinalis. Candida.

\begin{abstract}
SUMMARY
Objective: The aim of the study was to evaluate the antifungal activity of the essential oil of Rosmarinus officinalis (rosemary) on the growth kinetics of Candida albicans (ATCC289065) and C. tropicalis (ATCC40042). Methods: Into sterile glass tubes were inserted $1.8 \mathrm{~mL}$ of SabouraudDextrose broth, $0.2 \mathrm{~mL}$ of antifungal suspensions $\left(1.5 \times 10^{6}\right.$ $\mathrm{UFC} / \mathrm{mL}$ ) and $2 \mathrm{~mL}$ of the dilution of $R$. officinalis essential oil at $2 \%$ and $1 \%$. Posteriorly, $10 \mathrm{iL}$ of the test solutions were sowed on plates at the times: zero, 30,60 and 120 minutes. After incubation at $37^{\circ} \mathrm{C}$ for 24 hours, the counting of CFU/ $\mathrm{mL}$ for each sample was determined. Sodium hypochlorite solution at $0.5 \%$ and antimicrobial-free culture media were used as controls. Results: Upon C. albicans and C. tropicalis, $R$. officinalis intensified microbial death curve at 30 minutes $\left(<3.5 \times 10^{4} \mathrm{CFU} / \mathrm{mL}\right)$ and 120 minutes $\left(<9 \times 10^{4} \mathrm{CFU} / \mathrm{mL}\right)$, respectively. On C. albicans, statistically significant difference $(p<0.01)$ was found between growth control and total $\mathrm{CFU} / \mathrm{mL}$ promoted by the test products. Against $C$. tropicalis, a statistically significant difference $(p<0.01)$ was verified between the effect caused by $R$. officinalis and the total CFU/mL of growth control and sodium hypochlorite. Conclusion: It was concluded that Rosmarinus officinalis essential oil showed antifungal activity against $C$. albicans and $C$. tropicalis, and better effects were observed in a longer contact time.
\end{abstract}

\section{DESCRIPTORES}

Microbiology. Rosmarinus officinalis. Candida.

Graduando em Odontologia - Departamento de Clínica e Odontologia Social da Universidade Federal da Paraíba (UFPB), João Pessoa-PB, Brasil

2 Doutorando na Faculdade de Odontologia de Piracicaba no Departamento de Prótese e Periodontia da Universidade Estadual de Campinas (UNICAMP), Piracicaba/SP, Brasil.

UDoutoranda no Departamento de Dentística Restauradora na Faculdade de Odontologia de Araraquara da Universidade Estadual Paulista

3 (UNESP), Araraquara/SP, Brasil.

Professor Doutor Titular de Clínica Integrada - Departamento de Clínica e Odontologia Social da Universidade Federal da Paraíba (DCOS/UFPB), João Pessoa/PB, Brasil. 
$\mathrm{O}$ uso crônico de antimicrobianos pode alterar a microbiota residente da cavidade oral trazendo como consequência o crescimento de microorganismos potencialmente patogênicos. Esses fármacos são muito utilizados para o tratamento da candidíase e, a fim de restringir o uso de materiais sintéticos, tem-se aumentado os estudos para obtenção de métodos alternativos naturais para combater o crescimento de microorganismos (COSTA et al., 2009).

Sabe-se que as plantas são utilizadas para obtenção de medicamentos, as quais representam uma fonte de produtos naturais biologicamente ativos, com propriedades físico-químicas e biológicas adequadas para produção de fármacos (CLEFF, 2008).

$\mathrm{Na}$ literatura são encontradas diversas plantas medicinais, entre as quais podemos citar o Rosmarinus officinalis, conhecida popularmente como alecrim-decheiro, alecrim-das-hortas, alecrim-comum, alecrimverdadeiro e rosmaninho. O alecrim é uma planta encontrada na Região Mediterrânea e é cultivado em todo o território brasileiro, sendo muito utilizado para consumo (SOUSA, CONCEIÇÃO, 2007).

A atividade antifúngica do óleo essencial de $R$. officinalis (alecrim) já foi descrita por SACCHETTI et al., (2005), LIMA et al., (2006), POZZATTI et al., (2008), havendo variabilidade quanto ao tipo de microrganismos e técnica utilizada. Conhecendo o aumento das infecções fúngicas e diante da atividade do óleo essencial, assim como baixo custo e fácil acesso, há um interesse em realizar estudos a fim de obter novos antifúngicos com bases naturais.

Assim, o objetivo desse trabalho foi avaliar a atividade antifúngica do óleo essencial de Rosmarinus officinalis (alecrim) sobre a cinética do crescimento de Candida albicans (ATCC289065) e Candida tropicalis (ATCC40042).

\section{MATERIAL E MÉTODOS}

Realizou-se um estudo de abordagem indutiva, com procedimento comparativo estatístico e técnica de documentação direta em laboratório (LAKATOS, MARCONI, 2009). O estudo do efeito dos produtos testados sobre a cinética do crescimento de Candida foi realizado através do método de contagem de células viáveis para os fungos leveduriformes.

As cepas de referência utilizadas no estudo foram C. albicans (ATCC 289065) e C. tropicalis (ATCC40042), obtidas do Laboratório de Materiais de Referência do Instituto Nacional de Controle de Qualidade em Saúde (Fundação Oswaldo Cruz FIOCRUZ, Rio de Janeiro - RJ, Brasil). O processo de reativação se deu em caldo Sabouraud-Dextrose, a $37^{\circ} \mathrm{C}$ e a estocagem em agar Sabouraud-Dextrose $4 \%$ no Laboratório de Microbiologia Oral - Núcleo de Medicina Tropical do Centro de Ciências da Saúde da Universidade Federal da Paraíba. Para condução do estudo, suspensões fúngicas, sob a concentração $1,5 \times 10^{6}$ microrganismos $/ \mathrm{mL}$, foram preparadas em solução salina, comparável ao tubo 0,5 da Escala de MacFarland.

Os produtos empregados na avaliação do efeito sobre a cinética de crescimento das leveduras foram o óleo essencial de $R$. officinalis (Óleo essencial de Alecrim. Ferquima ${ }^{\circledR}$ Ind. e Com. Ltda. Vargem Grande Paulista - SP, Brasil), nas concentrações $1 \%$ e $2 \%$, bem como a solução de hipoclorito de sódio, na concentração 1\% (Solução de Milton - Solução 1\% de Hipoclorito de Sódio. Asfer-Ind. Química Ltda. São Caetano do Sul-SP, Brasil).

O óleo essencial de $R$. officinalis foi obtido na concentração pura e, para condução deste estudo, diluído segundo o método descrito por ALIGIANNIS et al., (2001), e LIMA et al. (2006). A densidade do produto natural foi considerada igual a $0,9 \mathrm{~g} / \mathrm{mL}$ e a diluição se deu pela adição de: $0,4 \mathrm{~mL}$ do óleo essencial em $10 \mathrm{~mL}$ de água destilada estéril e Tween 80 (agente emulsificante). O conjunto foi agitado durante 5 minutos em aparelho agitador de soluções tipo Vortex (Mod. AP56, Phoenix). A concentração final obtida foi de $4 \%$ e a concentração subsequente $(2 \%)$ foi alcançada mediante diluição seriada com água destilada. A solução de hipoclorito de sódio $1 \%$ (controle) foi utilizada em sua formulação comercial. Durante a realização do ensaio de cinética, a concentração dos produtos testados foi reduzida pela metade devido à mistura com o volume do meio de cultura e inóculo.

Em tubos de vidros estéreis foram inseridos: $0,2 \mathrm{~mL}$ das suspensões fúngicas $\left(1,5 \times 10^{6}\right.$ microganismos/ $\mathrm{mL}$ ); $1,8 \mathrm{~mL}$ de Caldo Sabouraud-Dextrose (duplamente concentrado); e $2 \mathrm{~mL}$ das diluições do óleo essencial (concentrações 2\% e 1\%), ou do controle (solução de hipoclorito de sódio $0,5 \%$ ), ou de solução salina (controle de crescimento).

Os tubos permaneceram incubados em estufa bacteriológica a $37^{\circ} \mathrm{C}$ no decorrer do ensaio. Nos tempos: zero, 30, 60 e 120 minutos, alíquotas de 10iL do conteúdo dos poços foram semeadas em placas de agar Sabouraud-Dextrose para posterior contagem de colônias e determinação do total de Unidades Formadoras de Colônia por mililitro (UFC/mL). As placas inoculadas forma incubadas em estufa bacteriológica a $37^{\circ} \mathrm{C}$, por 24 horas, em triplicata.

Após o período de incubação, o total de UFC/ $\mathrm{mL}$ para cada produto testado, nos tempos e concentrações predeterminadas, frente a cada cepa, será 
obtido a partir da contagem do total de colônias formadas sobre as placas de agar Sabouraud-Dextrose. Os dados (total de UFC/mL) foram tabulados no programa GraphPad Prism 5.0 (Programa GraphPad for Windows, San Diego, CA - USA), pelo qual se procedeu análise estatística pelo teste Kruskal-wallis e Dunn, sendo adotado nível de confiança de $95 \%$.

\section{RESULTADOS}

As Figuras 1 e 2 apresentam os valores obtidos na curva de morte microbiana para $C$. albicans $e C$. tropicalis, respectivamente, provocados pelo óleo essencial Rosmarinus officinalis nos tempos testados.

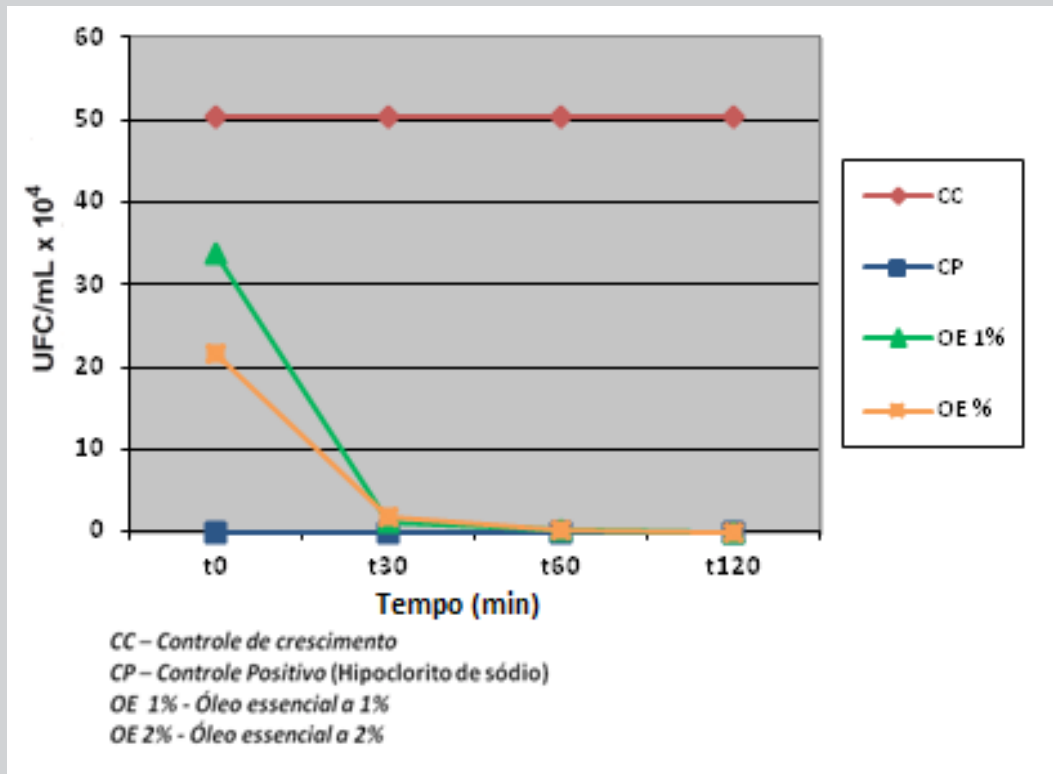

Figura 1: Curva de Morte Microbiana de C. albicans.

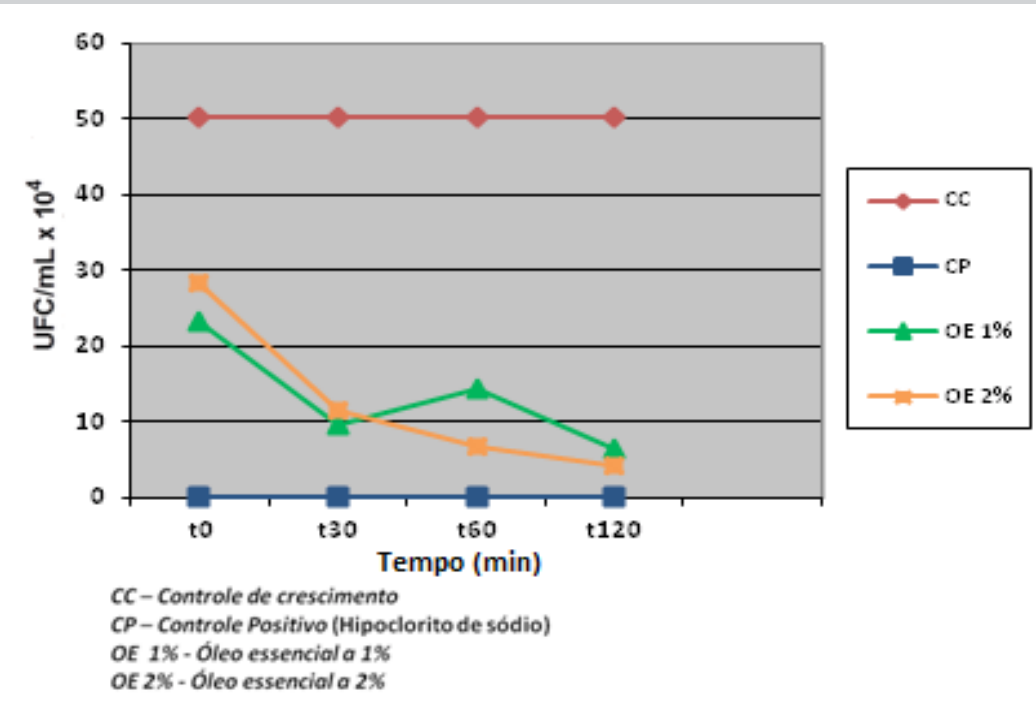

Figura 2: Curva de Morte Microbiana de C. tropicalis 


\section{DISCUSSÃO}

OLIVEIRA et al., (2008), e LEITE (2007), realizaram estudos em que determinaram a cinética de morte fúngica e bacteriana, respectivamente, e observaram o comportamento das cepas frente a óleos essenciais, havendo, em ambos estudos, acentuação de morte microbiana diante de tempos maiores. Encontramos poucos dados na literatura sobre a cinética de crescimento fúngico que permitam comparar e discutir com os resultados do nosso estudo.

No presente trabalho, observamos no gráfico 1 que a curva de cinética fúngica da cepa de $C$. albicans frente ao óleo essencial $R$. officinalis a $1 \%$ e a $2 \%$ apresentou-se decrescente no tempo 0 minutos. A partir de 30 minutos e nos tempos subsequentes, esse resultado foi semelhante ao controle positivo, se aproximando de zero UFC/ml. A concentração de $2 \%$ mostrou-se mais eficaz em relação àquela de $1 \%$.

Para C. tropicalis (Gráfico 2), no tempo 0 minutos houve decréscimo na curva, porém, nos tempos 30, 60 e
120 minutos, ela manteve-se com valores aproximados, não assemelhando-se ao controle positivo. Nos tempos 60 e 120 minutos, o óleo essencial a $2 \%$ mostrou-se mais eficaz, o que não foi observado nos tempos 0 e 30 minutos.

Nos ensaios de determinação de cinética fúngica, foram observados valores satisfatórios de UFC/ml quando comparados ao Controle de Crescimento, sendo estes sempre menores.

\section{CONCLUSÃO}

O óleo essencial de $R$. officinalis apresentou ação antifúngica sobre o crescimento de $C$. albicans e C. tropicalis, destacando-se maior efeito diante do maior tempo de contato. As cepas de C. albicans mostraramse mais susceptíveis, apresentando resultados mais satisfatórios para a atividade antifúngica do óleo essencial a $1 \%$ e $2 \%$.

\section{REFERÊNCIAS}

1. ALIGIANNIS N, KALPOUTZAKIS E, MITAKU S, CHINOU JB. Composition and Antimicrobial Activity of the Essential Oils of Two Origanum Species. J Agric Food Chem., 49(9):4168-4170, 2001.

2. CLEFF BM. Avaliação da atividade antifúngica do óleo essencial de Origanum vulgare L.frente a fungo de importância em veterinária com ênfase em candida spp [Tese de doutorado]. Porto Alegre: Universidade Federal do Rio Grande do Sul, 2008. 114p.

3. COSTAACBP, PEREIRA CA, FREIRE F, JUNQUEIRA JC, JORGE AOC. Atividade antifúngica dos extratos glicólicos de Rosmarinus officinalis Linn. e Syzygium cumini Linn. sobre cepas clínicas de Candida albicans, Candida glabrata e Candida tropicalis. Revista de Odontologia da UNESP, 38(2): 111-116, 2009.

4. LAKATOS EM, MARCONI MA. Fundamentos da metodologia cientifica. 3. ed., Sao Paulo: Atlas; 2009. $261 \mathrm{p}$.

5. LEITE AM. Avaliação da atividade biológica de óleos essenciais sobre espécies

6. bacterianas potencialmente causadoras de endocardite infecciosa, [Tese de doutorado]. João Pessoa: Universidade Federal da Paraíba; 2007. 113p.

7. LIMAIO, OLIVEIRARAG, LIMA EO, FARIAS NMP, SOUZA EL. Atividade antifúngica de óleos essenciais sobre espécies de Candida. Rev Bras Farmacogn., 16(2):197-201, 2006.

8. POZZATTI P, LORETO ES, LOPES PGM, ATHAYDE ML, SANTURIO JM, ALVES SH. Comparison of the susceptibilities of clinical isolates of Candida albicans and Candida dubliniensis to essential oils. Mycoses, 53(1):12-5, 2009.

9. SACCHETTIG, MAIETTI S, MUZZOLI M, SCAGLIANTIM, MANFREDINI S, RADICE M, BRUNI R. Comparative evaluation of 11 essential oils of different origin as functional antioxidants, antiradicals and antimicrobials in foods. Food Chem 91(4): 621-632, 2005.

10. SOUSATMP, CONCEIÇÃO DM. Atividade antibacteriana do alecrim (Rosmarinus officinalis L.). Ciênc. Veterin., 5(5): 7-13, 2007

\section{Correspondência}

Isabelle Cristine de Melo Freire

Rua Josias Lopes Braga, n 290

Bairro: Bancários

João Pessoa - Paraíba - Brasil

CEP: $58.051-800$

Email: icmf jp@hotmail.com 